\title{
Functional trait responses of aquatic macroinvertebrates to simulated drought in a Neotropical bromeliad ecosystem
}

\author{
OLIVIER DÉZERALD*, RÉGIS CÉRÉGHINO ${ }^{\dagger}$, BRUNO CORBARA $^{\S}$, ALAIN DEJEAN ${ }^{* \dagger}$ AND \\ CÉLINE LEROY** \\ *CNRS, Ecologie des Forêts de Guyane (UMR-CNRS 8172), Campus Agronomique, F-97379, Kourou Cedex, France \\ †Université de Toulouse, INP, UPS Laboratoire Ecologie Fonctionnelle et Environnement (ECOLAB), 31062, Toulouse, France \\ ${ }^{\ddagger}$ CNRS, ECOLAB (UMR-CNRS 5245), 118 Route de Narbonne, 31062, Toulouse, France \\ ${ }^{\S}$ Clermont Université, Université Blaise Pascal, BP 10448, 63000, Clermont-Ferrand, France \\ "CNRS, Laboratoire Microorganismes: Génome et Environnement (UMR-CNRS 6023), 63177, Aubière, France \\ **IRD, UMR AMAP (botAnique et Modélisation de l'Architecture des Plantes et des végétations), Boulevard de la Lironde, TA A-51/ \\ PS2, 34398, Montpellier Cedex 5, France
}

\section{SUMMARY}

1. The duration of the dry seasons in south-eastern Amazonia is expected to increase. Little is known of how freshwater assemblages respond to drought in the humid rainforests and of the extent to which they resist the absence of rainfall before the collapse of the system.

2. We manipulated rainshelters over tank-forming bromeliads (i.e. the interlocking leaf axils of these plants form wells that collect rainwater) to simulate an exceptionally long dry period (49 days, compared with a 10-year mean $\pm \mathrm{SD}$ annual maximum number of $17 \pm 5.3$ days without rainfall at the study site) and then a rewetting period. By sampling weekly over 3 months, we followed the dynamics of the representation of abundance-weighted traits in invertebrate assemblages in these treatment plants and in a control group.

3. The functional structure of assemblages was drought resistant until the water volume in the bromeliad pools dropped by $90 \%$, when there was a sudden shift in the functional trait structure due to the loss of most populations except the drought-resistant culicids. Traits related to life history, body size and preferred food showed significant responses to drought. There was a convergence in the functional traits of species surviving in dry plants, strengthening the idea that environmental filtering, rather than stochasticity, determines the functional trajectory of aquatic assemblages during drought.

4. At the end of the dry period, samples of the detritus potentially containing drought-resistant eggs/cysts (and eventually live larvae) were taken from the dry plants and rewetted in the laboratory, allowing us to distinguish resistant species from those requiring recolonisation via subsequent oviposition by adults from elsewhere. Patches of water-filled bromeliads persisting in the area provided the most important pool of colonists, and communities returned to the pre-disturbance state within 1-2 weeks of rewetting.

5. Our results suggest that the functional trait structure of invertebrate assemblages in bromeliads could remain stable under scenarios of precipitation change that would triple the duration of current dry periods at a local scale. Future experiments should evaluate how environmental factors might alter the tipping point between resistance to drought and a collapse in ecosystem processes.

Keywords: food webs, precipitations, rainforests, resistance/resilience, tipping point

Correspondence: Olivier Dézerald, CNRS, Ecologie des Forêts de Guyane (UMR-CNRS 8172), Campus Agronomique, F-97379 Kourou Cedex, France. E-mail: olivier.dezerald@gmail.com 


\section{Introduction}

Anthropogenic climate change is predicted to increase the frequency and intensity of extreme climatic events such as severe droughts (IPCC, 2013). Ecosystems will not only be affected through temperature-related changes in physiological rates (Sheldon, Yang \& Tewksbury, 2011), but also through disruption of rainfall patterns (Dejean et al., 2011; Naiman \& Dudgeon, 2011). In South America, the northern and eastern coasts and central Amazonia are predicted to become drier (seasonal estimates range from 10 to $50 \%$ ), whereas the western equatorial and south-eastern coasts are predicted to become wetter (Karmalkar, Bradley \& Diaz, 2008; IPCC 2013, Magrin et al., 2014).

The hydrology of freshwater ecosystems is expected to be affected by altered precipitation patterns (Lake, 2011), with important consequences for aquatic communities and the ecosystem processes they support (Sim et al., 2013). Functional traits, the biological, physiological and ecological attributes of organisms, determine how individuals interact with their environment (Violle et al., 2014). Assuming that the biological assemblage of any given ecosystem integrates the spatial-temporal variability of the environment (Southwood, 1988), taxa with certain combinations of physiological-ecological adaptations are believed to be selected by the dynamics of the local and regional environment. For instance, macroinvertebrates assigned to functional groups based on life history strategies and/or on adaptations to acquire food have proven relevant to track changes in ecosystem processes in relation to drought (Gascon et al., 2010), while the survival of large-bodied species feeding near the apex of food webs may be particularly affected by drought (Power, Parker \& Dietrich, 2008; Bogan \& Lytle, 2011; Ledger et al., 2011). Conversely, traits that confer resistance and/or resilience to drought (e.g. small body size, short generation times, asexual reproduction, eggs, cysts) should be selected through environmental filtering (Dolédec et al., 2006; Sim et al., 2013). Hence, while models that link environmental conditions to community structure are needed to predict ecosystem responses to drought, the recent literature points towards the idea that knowledge of the changes in the functional traits represented in food webs, rather than changes in species occurrence and/or abundance, will greatly improve our ability to predict the impact of environmental change on ecosystems, and, more importantly, tipping points for any particular ecosystem process, or state (Statzner et al., 2001; McGill et al., 2006; Poff et al., 2006; Lamanna et al., 2014).
The absence of rainfall may not translate into immediate ecological responses within freshwater systems, because thresholds in the movement, distribution and/or quality of water that trigger functional shifts depend on the capacity of the system to buffer changes in precipitation. Manipulating rainfall at the whole ecosystem level is impractical in rivers, lakes or ponds, however, so that the methodological advantages of pre-post-test design and treatment versus control groups conferred by experimental studies are not achievable in large macrocosms. Hence, most of our current knowledge of environmental filtering of functional traits by drought has come from studies of intermittent rivers (Reznickova, Paril \& Zahradkova, 2007; Sangiorgio, Fonnesu \& Mancinelli, 2007) and temporary wetlands (Bond, Lake \& Arthington, 2008; Sim et al., 2013), where authors took the opportunity of seasonal dry : wet cycles to document shifts in trait composition during drying and rewetting phases. In addition, assembling data on the functional traits represented in food webs is a challenging issue, first because many food webs are too complex or spatially diffuse to allow adequate sampling and second because most ecosystem types lack natural replication (even well-delineated ponds and lakes are too diverse to form true replicates). Natural aquatic microcosms such as phytotelmata (water held in plants) form alternative models (reviewed in Srivastava et al., 2004).

Bromeliads (Bromeliaceae) are flowering plants represented by 3140 species native mainly to the neotropics (Givnish et al., 2011). The interlocking leaves of tankforming bromeliads form rosettes that collect rainwater (from a few millilitres to a few litres). This water source, in addition to leaf litter inputs from the bromeliad itself, provides a habitat for aquatic organisms ranging from prokaryotes to invertebrates which together constitute an aquatic community (see Brouard et al., 2012 for details). The food webs within tank-forming bromeliads contain several trophic levels, are easy to sample completely, are widely distributed in the neotropics and are replicated many-fold in nature (Richardson, 1999). Owing to these features, using manipulative experiments, these natural microcosms are relevant model systems for investigating the response of aquatic communities to disrupted precipitation.

Resistance and/or resilience to severe drought is inherent in, for instance, Mediterranean or arid land communities (Boersma et al., 2014; Céréghino et al., 2012). However, little is known of how biological communities respond to drought in rainforests, and of the extent to which Neotropical communities resist the 
prolonged absence of rainfall before a tipping point is reached. Our experimental study was conducted in French Guiana (eastern Amazonia). We studied how complete drying and then rewetting affected tankbromeliad communities in terms of temporal changes in the trait modalities (where a "modality" is one of a number of categories that a trait can take) represented. We then identified thresholds in community resistance and resilience in relation to drought-induced changes in hydrology. We followed changes in the abundanceweighted traits represented in treatment and control groups of plants over 3 months. Assuming that functional traits reflect environmental conditions that may be shared by many species (Céréghino et al., 2012), we expected that (i) either community resistance or vulnerability to drought would result from synchronous response of co-occurring species (i.e. most species resist, decline in numbers or collapse simultaneously) and (ii) environmental filtering would generate a convergence in the functional traits of surviving species under the harshest conditions.

\section{Methods}

\section{Study site and bromeliad species}

Our experiment was conducted from March 2014 to July 2014, in a lowland rainforest near the Petit-Saut Dam in French Guiana $\left(5^{\circ} 03^{\prime} 43^{\prime \prime} \mathrm{N}, 53^{\circ} 02^{\prime} 46^{\prime \prime} \mathrm{W}\right.$; altitude $\left.<80 \mathrm{~m}\right)$. The climate is tropical moist with $3000 \mathrm{~mm}$ of annual precipitation, with little variation in seasonal temperature (monthly averages from $20.5^{\circ} \mathrm{C}$ to $33.5^{\circ} \mathrm{C}$ ), and relative humidity (70-100\%). There is a major reduction in rainfall between September and November and another shorter and more irregular dry period in March. A preliminary analysis of daily rainfall records in our study area over the past 10 years (see Dejean et al., 2011) showed that the annual mean \pm SD maximum number of consecutive days without rainfall in a dry season is $17 \pm 5.3$. The only tank-bromeliad species at our study site was Vriesea splendens. The vegetative traits, aquatic milieu and invertebrate assemblages in this common bromeliad in French Guiana were described in Jabiol et al. (2009), Brouard et al. (2012) and Leroy et al. (2013).

\section{Experimental design and invertebrate sampling}

We selected 12 mature bromeliads (excluding flowering stages) that were similar in terms of their vegetative traits (size, leaf display, number of leaves forming wells, etc.). Six of these plants were allowed to collect rain nat- urally (control), and six were subjected to a "drought" treatment. The water and air temperature were recorded at each visit using digital probes, to verify that there was no significant difference between air and water temperature; that is, that water temperature was not confounded with water volume. The $\mathrm{pH}$ probes could not be used with the smallest water volumes $(<0.5 \mathrm{~mL}$ at the end of the dry phase); therefore, to ensure consistency in methods, the water $\mathrm{pH}$ was measured using $\mathrm{pH}$ indicator papers (accuracy: 0.3 units; range: 3.9-6.9). The mean weekly precipitation at the study site was calculated from daily rainfall records obtained with a rain gauge. The experiment lasted 15 weeks and was divided into two phases. The first phase (7 weeks) consisted in simulating an exceptionally long dry period by installing a rainshelter (transparent plastic tarps) above six treatment plants. This phase ended when the last treatment plant completely dried out (when we could not detect any water in the leaf wells). We then removed the rainshelters and refilled all treatment plants manually to their maximum water volume with rainwater. This initiated the rewetting phase ( 8 weeks) where plants were allowed to collect rainfall naturally like the control plants.

The invertebrate species composition and density in each of the 12 plants were monitored weekly. Invertebrates were identified to species or morphospecies and counted directly in the field using magnifying glasses (x6) and a headlamp (all organisms $>0.5 \mathrm{~mm}$ ), and immediately returned to their original leaf/plant with the corresponding water volume. To sample the water and aquatic invertebrates in the wells (leaf axils) of each plant (excluding the outer, senescent leaves), we used 10- to 1-mL micropipettes with the end trimmed to widen the orifice. The actual volume $(\mathrm{V}, \mathrm{mL})$ held by each leaf forming a well was measured using a graduated cylinder. This non-destructive sampling technique has already been used successfully by us (Céréghino et al., 2011; Dézerald et al., 2013) and others (Jocque et al., 2010).

Resistant stages versus recolonisation in assemblage recovery after drought

At the end of the dry period, a fraction of the fine detritus potentially containing drought-resistant eggs/cysts (and eventually live larvae) was sampled from all dry (treatment) plants and rewetted in test tubes in the laboratory, to allow us to identify the species representing the resistant forms and those requiring subsequent oviposition by adults from elsewhere. A small volume of 
distilled water $(2 \mathrm{~mL})$ was added to the mature leaf axils (i.e. excluding the central reservoir in the process of formation, and the outermost senescent leaves) in each of the six dry plants in order to rewet the fine detritus. This water (c. $12 \mathrm{~mL}$ per plant) was then sucked in and out three times with a micropipette to homogenise the fine detritus, placed in 50-mL test tubes, and brought to the laboratory where the samples were kept at ambient temperature (c. $25^{\circ} \mathrm{C}$ ). Any live larvae were immediately sorted, identified and counted. The samples were then checked each day for newly hatched larvae (denoting the presence of resistant eggs), which were also identified and counted. Species found in these tubes evidently had the ability to resist drought, whereas other species presumably recolonised the rewetted bromeliads via immigration from the surrounding area.

\section{Macroinvertebrate functional traits and data analyses}

The weekly monitoring of invertebrate species composition and abundance allowed us to build a [samples $\times$ invertebrate morphospecies] abundance matrix (samples are in rows and morphospecies in columns), where each "sample" is a bromeliad at a given date. The functional traits for each taxon were obtained from our own observations of live and preserved specimens, as well as previous publications (Céréghino et al., 2011; Dézerald et al., 2013). We focussed on morphological and trophic attributes (e.g. body size, food, feeding habits) as well as life history (e.g., resistant forms, with an aquatic or terrestrial adult, cohort production intervals), these traits being often seen as important drivers of species' responses to droughts (Fenoglio et al., 2007). Categories used for the different traits are listed in Table 1. Information on the biological traits was then structured using a fuzzy-coding technique (Chevenet, Dolédec \& Chessel, 1994): scores ranged from " 0 ", indicating "no affinity", to "3", indicating "high affinity" for a given trait category. This procedure allowed us to build the [invertebrate species $x$ traits] matrix (invertebrate species are in rows and traits in columns; see also Dedieu et al., 2015). We then combined both matrices by matrix multiplication to upscale trait information to the community level in the form of a [samples $x$ traits] matrix, where each sample represents a bromeliad at a given date (in rows), and the abundance-weighted traits are in columns (Pillar et al., 2009).

If drought affected the functional trait composition of macroinvertebrate assemblages to some extent, then treatment samples should deviate from control samples in ordination space in terms of the weighted average of their species traits. To test this assumption, and to further identify functional traits that were significantly affected, a fuzzy correspondence analysis (FCA) was conducted on the log-transformed [samples $\times$ traits] matrix (Chevenet et al., 1994). The aim of the FCA is to ordinate the samples according to their abundanceweighted trait modalities, and to schematise variations in the combinations of functional traits of macroinvertebrate communities in the ordination space. The significance of each trait modality to the functional response of the community (axes 1 and 2 of the FCA accounting for $89 \%$ of the overall variance, see Results) was then assessed using Pearson correlation coefficients. MannWhitney tests were used to test significant differences in sample distribution in the FCA according to control and treatment groups using coordinates of samples on the most significant axis.

To summarise temporal trends in abundance-weighted trait modalities, and to identify thresholds in community resistance and resilience in relation to drought-induced changes in water level, the mean proportions of abundance-weighted trait modalities were plotted against time for each trait for control and treatment bromeliads. Abiotic difference among treatment and control plants was compared between the beginning (week 1), the dry period (week 5) and the end of the experiment (week 15) using Mann-Whitney and Wilcoxon tests. All uni- and multivariate analyses were conducted using the $R$ software version 2.15.2 (R Development Core Team, 2014).

\section{Results \\ Temporal changes in physicochemical variables}

The mean daily rainfall $( \pm S D)$ was $8.68 \pm 2.1 \mathrm{~mm}$ during the study period. The water volume held by control plants remained almost constant throughout the 15 weeks $(90.7 \pm 2.9 \mathrm{~mL}$ ) (Fig. 1). Treatment plants held $87.9 \pm 7.4 \mathrm{~mL}$ of water at the beginning of the experiment, and $0.76 \pm 0.3 \mathrm{~mL}$ after $4.66 \pm 0.44$ weeks (Fig. 1a). Owing to the small size and high terrestrial : aquatic surface ratio of bromeliads, water temperature closely followed air temperature and was not affected by our treatment. The difference between water and air temperatures was $<0.8{ }^{\circ} \mathrm{C}$ in treatment and control plants, regardless of the experimental phase (MannWhitney and Wilcoxon tests, all $W>18$, all $P>0.42$ ). The mean rainwater $\mathrm{pH}( \pm \mathrm{SD})$ was $5.3 \pm 0.23$ throughout the experiment. However, $\mathrm{pH}$ decreased significantly during the drought period in all treatment plants compared to the control ones (mean $\mathrm{pH}=4.6 \pm 0.07$

(C) 2015 John Wiley \& Sons Ltd, Freshwater Biology, 60, 1917-1929 
Table 1 Functional traits, trait modalities and functional trends (" + " = increase or " $"$ " = decrease with decreasing effect of drought) resulting in a significant Kendall's Tau coefficient between the proportion of trait modalities and the first and second axes scores in the fuzzy correspondence analysis

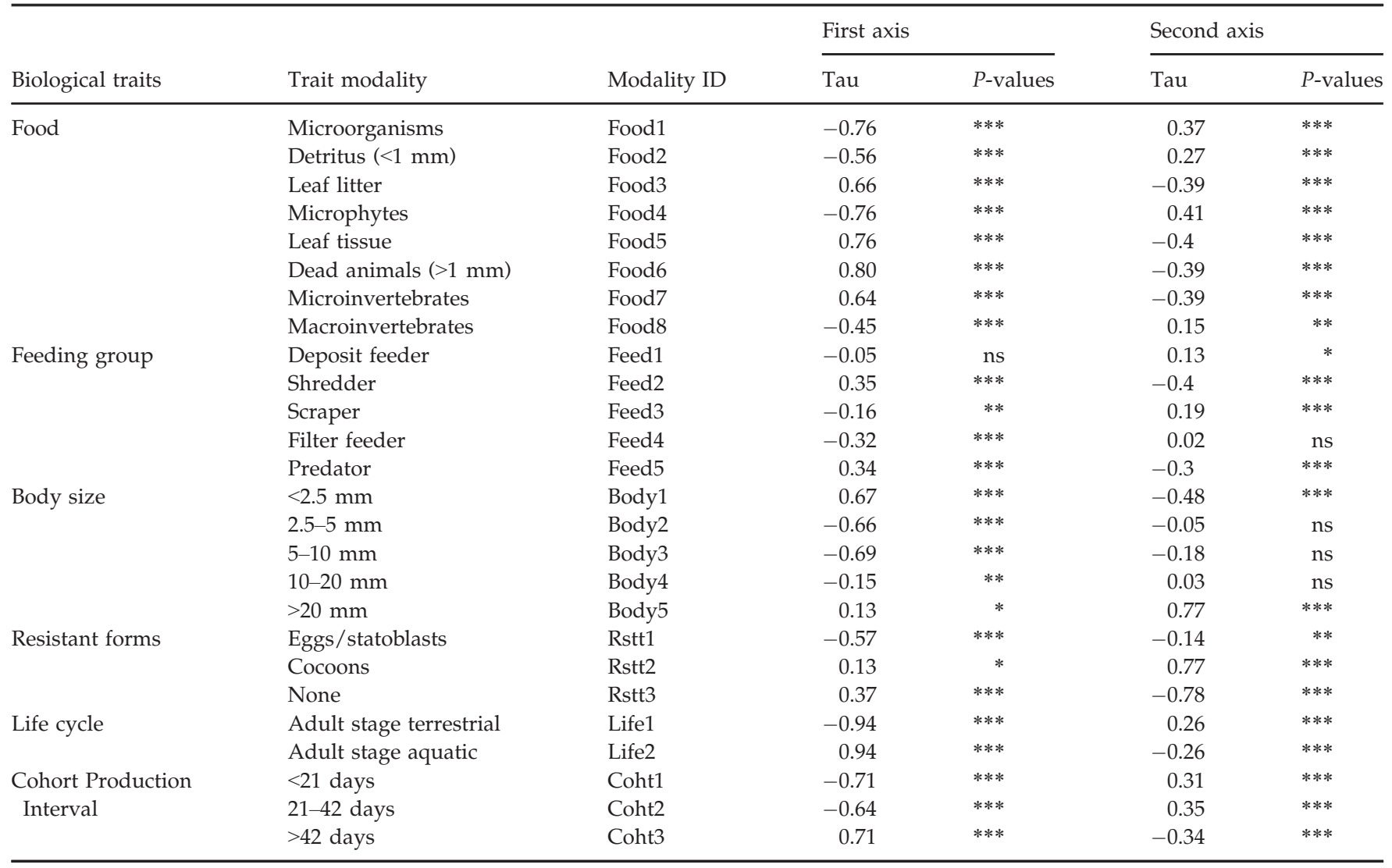

Kendall's Tau coefficient tests; $* P<0.05 ; * * P<0.01 ; * * * P<0.001 ;$ ns not significant.

and $5.0 \pm 0.02$, respectively; $W=36, P=0.004$ ), but were not significantly different at the beginning and at the end of the experiment (all $W>15$, all $P>0.68$; Fig. 1b). Because $\mathrm{pH}$ was measured with papers accurate to only 0.3 units and had a relatively small range (3 units), we remain cautious on the significance of this last results. Nevertheless, we note that standard deviations of our estimates did not overlap during the drought phase (Fig. 1b).

\section{Fuzzy-coding analysis of species trait combinations}

The first and second axes of the FCA explained 76.0 and $13.2 \%$ of the total variance in trait composition of the aquatic community, respectively. The first axis (FCA1) displayed a shift in mean community traits from control (right) to treatment plants (left) (Fig. 2), and there was a significant difference between plant groups (control versus treatment) along this axis (Mann-Whitney and Wilcoxon test, $W=1102, P<0.0001)$. The driest samples within the treatment group were located on the left side of the scatterplot. Significant correlations were found between the scores of the first two axes and most trait categories (Fig. 2). Overall, traits related to life history (cohort production interval, life cycle type, resistant forms) and food preference were the most significant on the first axis, while traits related to body size and resistant forms showed gradients along the second axis (Kendall's Tau coefficient tests, see Table 1). There was a higher proportion of organisms with aquatic immature stages and terrestrial adults and with short generation times in treatment plants, as well as those feeding upon microorganisms, microphytes and fine detritus $<1 \mathrm{~mm}$ in size. This is consistent with the presence and numerical dominance of Wyeomyia culicids in the treatment samples (see below). The centroid of the treatment samples in the ordination space is shifted to the left area of the FCA axis 1, compared to the centroid of the control samples. By superimposing Fig. 2a.5,b, it becomes apparent that treatment samples are characterised by organisms with aquatic larvae-pupae and terrestrial adults, for example Wyeomyia culicids. Conversely, control samples had higher proportions of organisms with both aquatic immature and adult stages, among which 

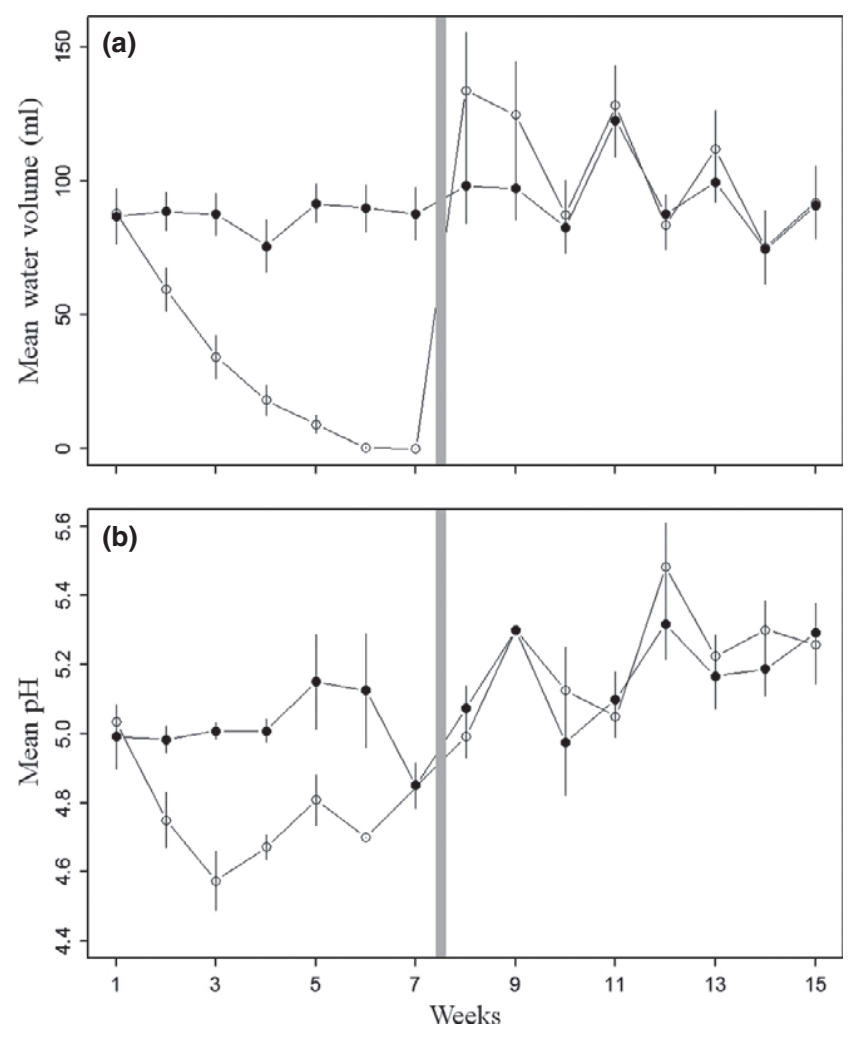

Fig. 1 Weekly changes in mean $( \pm S D)$ (a) water volume $(m L)$ and (b) $\mathrm{pH}$ in control and treatment plants (solid and open circles, respectively). The grey bar indicates beginning of the rewetting period (see text).

the very abundant Aulophorus superterrenus (Haplotaxida, Naididae) and Elpidium bromeliarum (Podocopida, Lymnocytheridae) were dominant (Fig. 2a.5,b). Assemblages in these plants were also characterised by higher proportions of species with longer generation times, which fed either upon leaf litter or other invertebrates (Fig 2a.6,a.1, respectively; Fig. 2b).

\section{Temporal changes in abundance-weighted trait modalities}

In the control group, the proportions of abundanceweighted modalities in each functional trait remained almost constant over the 15-week experimental period (Figs $3 a, c, e, \& 4 a, c, e)$. This finding also suggests that our weekly visits and resampling of invertebrates did not generate a bias in the observed patterns. In the treatment group, the distributions of trait modalities were not affected during the first 5 weeks of drought, when they remained similar to those observed in the control group. This pattern means that communities resisted drought, despite a large $(89.8 \%)$ decrease in water volume available. In the sixth week, when the available water volume dropped to $<1 \mathrm{~mL}$ (i.e. a $99 \%$ decrease compared to the
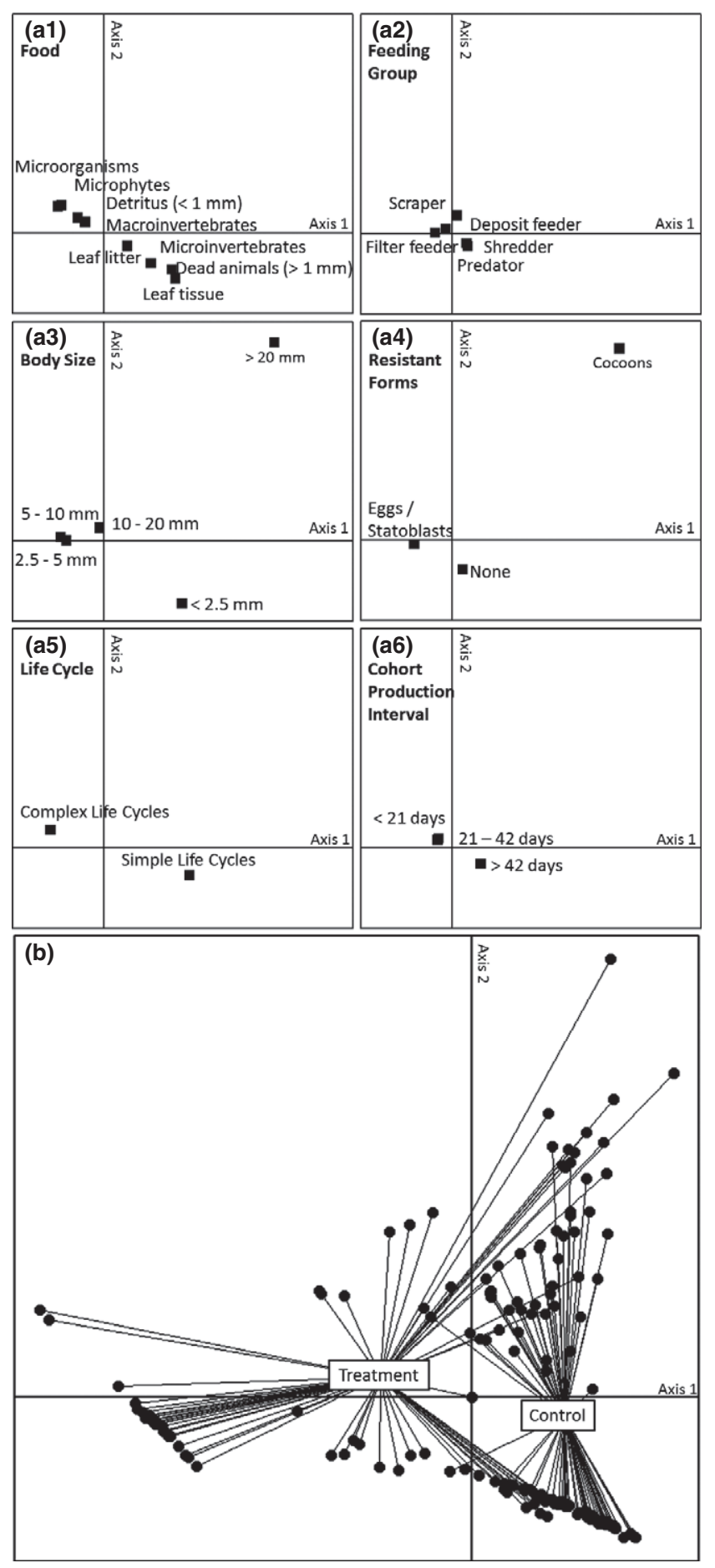

Fig. 2 Fuzzy correspondence analysis (FCA) of functional trait composition in samples originating from control and treatment plants: (a1-a6) distribution of species trait modalities on the first two axes, (b) ordination of samples on the first two axes of the FCA, and grouping of samples according to treatment and control bromeliads. Each panel a1 to a6 can be compared to (or supersimposed on) the distribution of samples represented in (b), to interpret the set of traits modalities associated with the various areas (or macroinvertebrate communities) of the ordination space. Modalities are positioned at the weighted average of their species. 
Fig. 3 Changes in the mean proportions of abundance-weighted traits in control (left panels; a, c, e) and treatment plants (right panels; $b, d, f$ ) over time: $a$, $\mathrm{b}=$ food; $\mathrm{c}, \mathrm{d}=$ functional feeding groups; $\mathrm{e}, \mathrm{f}=$ body size. Abbreviations in black boxes are the identities of trait modalities as shown in Table 1. The dotted line indicates when the simulated drought had persisted for twice as long as the usual prevailing dry periods in the area.
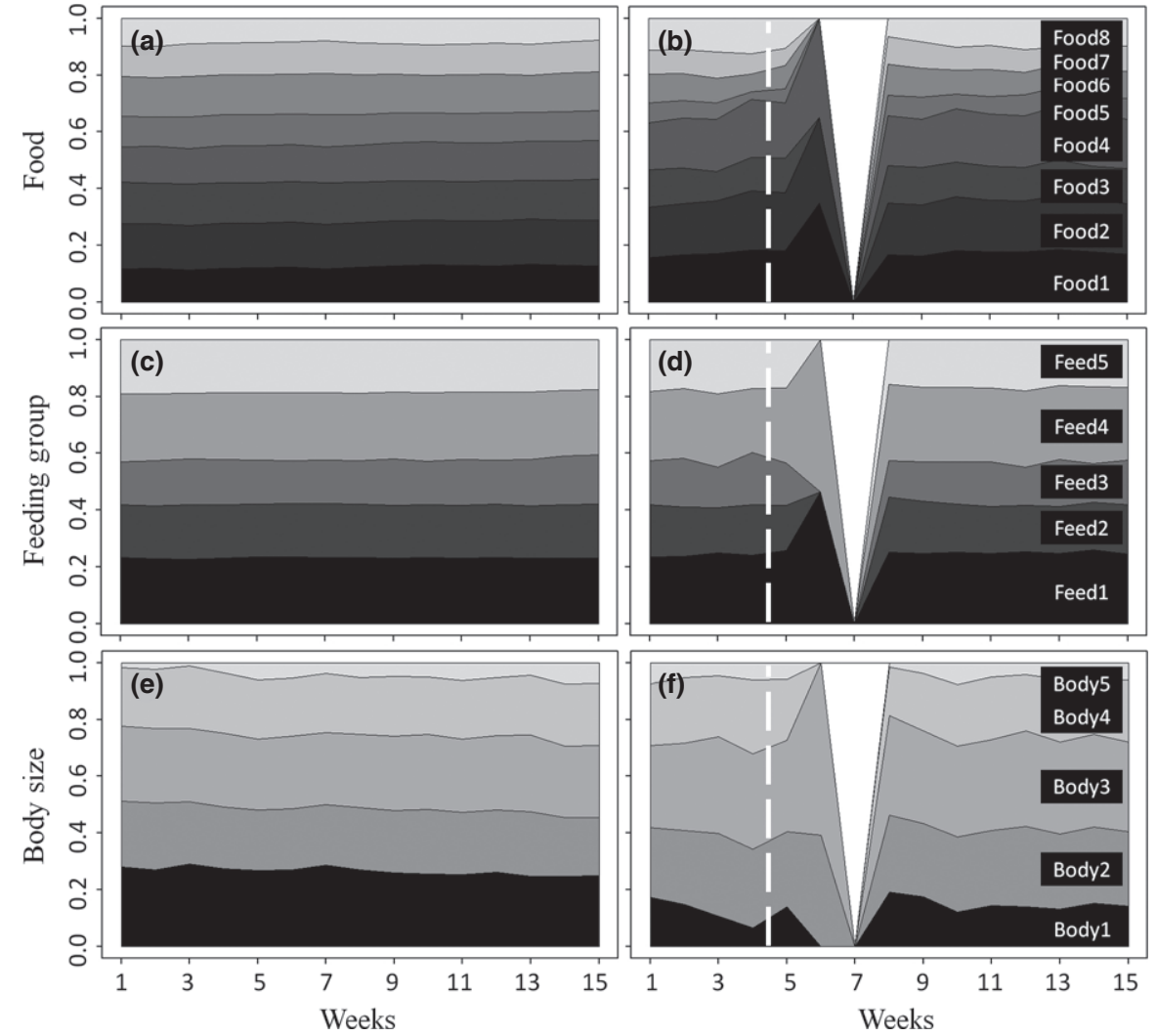

initial volume), only two culicid species, Wyeomyia (Dodecamyia) aphobema and Wyeomyia (Hystatomyia) lamellata, were found active in the bromeliads. These species are both filter and deposit feeders, characterised by short generation times ( $<21$ days) and with complex life cycles. The final instar larvae are $<10 \mathrm{~mm}$ in length, and adults lay drought-resistant eggs (see below). Proportions of these trait modalities therefore peaked at 6 weeks (Figs 3 $\& 4$ ), while other trait modalities disappeared. In the seventh week, all treatment plants dried out. After refilling the plants with rainwater, within $<2$ weeks, there was a return to a distribution of trait modalities, similar to that in controls, so that assemblages recovered rapidly. The rest of the rewetting phase (weeks 8-15) was characterised by a steady proportion of abundance-weighted trait modalities, much like in control plants. Our results mainly illustrate changes in the relative proportion of trait categories, but proportions can remain almost constant if co-occurring species/traits increase or decrease in abundance simultaneously.

\section{Resistant stages versus recolonisation in assemblage recovery after drought}

The local taxon pool was composed of 22 morphospecies (Table 2). Seven of these taxa were found in tubes that contained rewetted detritus taken from the completely dry plants at week 7 (Fig. 5). Among these seven taxa, only Wyeomyia (Dodecamyia) aphobema and Wyeomyia (Hystatomyia) lamellata hatched as first instar larvae in our tubes a few days after collecting the detritus, revealing that these species lay drought-resistant eggs in bromeliads. The five remaining morphospecies were already present as active larvae in the detritus, revealing their ability to survive drought at this stage. Elpidium bromeliarum ostracods and both Wyeomyia culicids were the dominant species (Fig. 5). There was less than one individual per plant on average of Cyphon sp., Corethrella sp., Ceratopogonidae sp1 and Orthocladiinae sp. Other species present in the local species pool were not found in tubes containing rewetted detritus. Therefore, the latter species probably colonised the bromeliads through adult oviposition and/or phoresy after rewetting.

\section{Discussion}

Intensification in the tropical Atlantic north-south sea surface temperature gradient is expected to enhance the duration of the dry seasons in south-eastern Amazonia, including the Guiana Shield (IPCC, 2013). In our study, we created conditions that simulated the impact of a 49-day-long drought on Neotropical invertebrate 


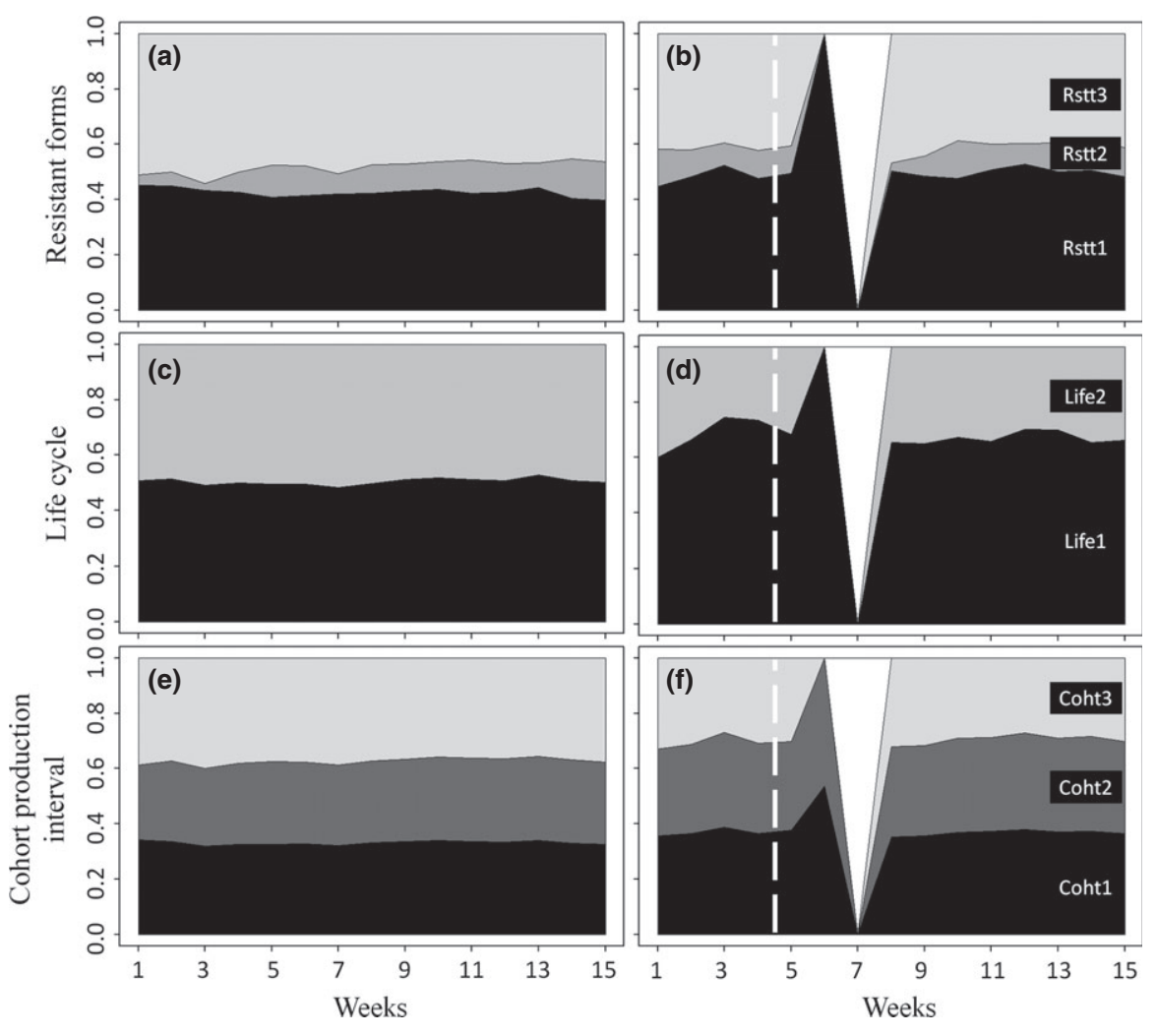

Fig. 4 Changes in the mean proportions of abundance-weighted traits in control (left panels; a, c, e) and treatment plants (right panels; $b, d, f): a, b=$ resistant forms; c, d = life cycle; e, $\mathrm{f}=$ cohort production interval (CPI, days). Abbreviations in black boxes are the identities of trait modalities as shown in Table 1. The dotted line indicates when the simulated drought had persisted for twice as long as the usual prevailing dry periods in the area.
Table 2 The aquatic macroinvertebrates forming the species pool at our study site

\begin{tabular}{lll}
\hline Order & Family & Species \\
\hline Diptera & Culicidae & Wyeomyia aphobema \\
& & W. lamellata \\
& W. robusta \\
& Microculex stonei \\
& & Anopheles nevai \\
& & Toxorhynchites sp. \\
& Corethrellidae & Corethrella sp. \\
& Ceratopogonidae & Bezzia sp. \\
& & Ceratopogonidae sp1 \\
& Ceratopogonidae sp2 \\
& Ceratopogonidae sp3 \\
& Chironomidae & Orthocladiinae sp. \\
& & Tanypodinae sp. \\
& & Tanytarsinae sp. \\
& Tipulidae & Trentepohlia sp. \\
& Psychodidae & Telmatoscopus sp. \\
& Brachycera spp. \\
Odonata & Coenagrionidae & Coenagrionidae sp. \\
Coleoptera & Scirtidae & Cyphon sp. \\
Hemiptera & Veliidae & Paravelia sp. \\
Haplocopida & Limnocytheridae & Elpidium bromeliarum \\
Haxida & Naididae & Aulophorus superterrenus \\
\hline & &
\end{tabular}

communities, that is about three times the maximum number of consecutive days without rainfall under ambient climate. This study is original because we followed the community trait structure over time, thus

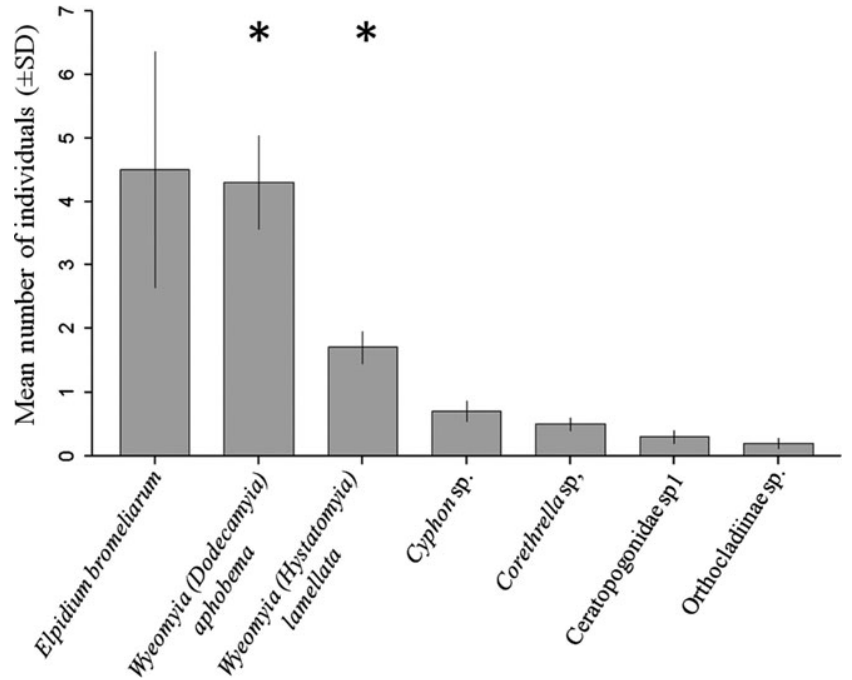

Fig. 5 Invertebrate species found in rehydrated samples, ranked by decreasing mean $( \pm \mathrm{SD})$ abundance (from left to right). Asterisks indicate species that hatched from drought-resistant eggs (see text).

allowing us to determine possible tipping points in ecosystem processes in relation to hydrological thresholds. Our results showed that the functional structure of communities was drought resistant until the water volume in the bromeliads dropped by $90 \%$. Beyond this point, there was a sudden shift in the trait structure of communities due to the loss of most populations, except 
the drought-resistant culicids, and then communities returned quickly to the pre-disturbance state during the rewetting period, suggesting strong resilience.

At our study site, it took up to 7 weeks to dry out a mature $V$. splendens in the understorey. Zotz \& Thomas (1999) found that Guzmania monostachya, an overstorey bromeliad of similar leaf display and water volume, dried out in $<10$ days in Panama, suggesting that the relationship between rainfall and hydrology in bromeliad pools depends on both study locations and bromeliad species. Regardless of the time needed to dry out a plant, the biological diversity of the system was expected either to decrease gradually with increasing drought severity/duration (drought vulnerability hypothesis) or to remain more or less constant until an abrupt shift occurred (drought resistance hypothesis; Boersma et al., 2014). The stability in the proportion of abundance-weighted trait modalities during the dry phase of our experiment supports the drought resistance hypothesis of bromeliad invertebrate communities in the understorey of a Neotropical forest. Interestingly, treatment samples that represented the harshest environmental conditions (end of the dry phase) showed the lowest dispersion in ordination space in terms of the weighted average of their species traits (left area of FCA axis 1 in Fig. 2b), indicating that (i) species from the local pool that were unable to withstand severe drought were eliminated, and therefore, (ii) environmental filtering led to a convergence in the functional traits of surviving species. Indeed, we observed that most species declined progressively in numbers during drought until only the most resistant species remained (Wyeomyia culicids), suggesting that the taxonomic structure of communities is vulnerable to drought and strengthening the idea that niche-selection filtering rather than stochasticity determines the functional trajectory of communities during drought (Chase, 2007).

Trait modalities related to life history (life cycle type, cohort production interval, resistant forms), morphological attributes (body size) and preferred food did well at discriminating communities from the control and treatment group of plants. To some extent, the significant responses of most traits to drought (Table 1) may reflect coincidence among traits within groups of taxa. For instance, long-lived organisms (Coleoptera Scirtidae, Diptera Tipulidae) also processed coarse detritus (Merritt, Cummins \& Berg, 2008). Incidentally, these species tended to decline first, and this may have temporarily decreased decomposition rates in tank bromeliads.

Along with habitat contraction during dry periods, invertebrates faced changes in their chemical environ- ment. The $\mathrm{pH}$ declined during drought in treatment plants, but the influence of $\mathrm{pH}$ on invertebrate occurrence (notably aquatic insects) could vary among taxonomic groups (Clark, Flis \& Remold, 2004) and could not be ascertained here. We note, however, that the range of $\mathrm{pH}$ recorded in our plants remained within the limits of $\mathrm{pH}$ values measured with $\mathrm{WTW}^{\circledR}$ probes in un-manipulated, water-filled V. splendens in French Guiana (4.3-5.6, personal observations). An important environmental variable that was not taken into account for technical reasons was dissolved oxygen $\left(\mathrm{O}_{2}\right)$. Probes were inefficient at measuring $\mathrm{O}_{2}$ concentrations in small volumes; however, measurements with $\mathrm{WTW}^{\circledR}$ probes in other Vriesea splendens in the area revealed that $\mathrm{O}_{2}$ concentrations varied between 50 and $7 \%$. Assuming a decrease in dissolved $\mathrm{O}_{2}$ with habitat contraction, we note that the community was dominated by species breathing with a siphon in drying plants (Culicidae), whereas individuals breathing with caudal lamellae and/or tegument were eliminated (e.g. odonates, tipulids). Finally, although this aspect was not investigated in this study, changes in species interactions are likely to moderate the response of functional traits to drought. The concentration of individuals in smaller water volumes might notably increase antagonistic interactions (Srivastava, 2006), thus selecting traits related to competition, predation and/or predator avoidance (Hammill et al., 2015).

During the rewetting period, communities could respond in two possible ways, that is return to a pre-disturbance state, demonstrating resilience, or shift to a new equilibrium (Bogan \& Lytle, 2011). In our study, the functional structure of aquatic communities returned to the pre-disturbance state in 1-2 weeks after the removal of the rainshelters, suggesting a strong resilience to an exceptional drought event, much like other invertebrate communities elsewhere, for instance in streams (Boulton, 2003; Lake, 2003; Sim et al., 2013). The rapid community resilience in our treatment plants can be explained by behavioural and physiological responses to drought, on the one hand, and by environmental conditions that fostered recovery on the other. In terms of species' responses, the rewetting of dried out detritus in test tubes showed that only a few species are able to survive in residual moisture and withstand dehydration in the active larval or adult stage. This applies notably to the ostracod Elpidium bromeliarum (Lymnocytheridae) (Lopez et al., 2005). The production of drought-resistant eggs in Wyeomyia species [here Wyeomyia (Dodecamyia) aphobema and Wyeomyia (Hystatomyia) lamellata] is not common and is new for bromeliad-dwelling Wyeomyia (see Juliano \& Lounibos, 2005). The set of species found in our 
rehydrated samples represented the main sources of "internal resilience" in the system, while those species not found in our test tubes may have responded to the dry phase by simply leaving bromeliad pools by emerging or crawling, or by dying. Our methods did not allow us to clearly separate mortality from behavioural response to drought (Williams \& Hynes, 1974). However, we know that some bromeliad-dwelling invertebrates, notably Scirtidae (Cyphon sp.), odonates (Coenagrionidae) and Tipulidae (Trentepohlia sp.), are able to move from leaf to leaf to find water (personal observations). Owing to their typical dispersal mode, and whatever their response during the dry phase, we conclude that this second set of species contributed to the "external resilience" of the system, in that they mostly recolonised rewetted bromeliads through adult oviposition (e.g. Culicidae with very short generation times such as Anopheles neivai, Microculex stonei) and through phoresy (e.g. Aulophorus superterrenus, Annelida, see Lopez et al., 2005). Most organisms gradually recolonised treatment plants over time, until the assemblage and food-web structure did not differ from that of the control plants in terms of species composition and abundance. However, not all species recovered at a similar rate. Within the first 2 weeks of rewetting, filter feeders, notably Wyeomyia species, outnumbered other species. Conversely, Corethrellidae (the numerically dominant predator in control plants) returned to their pre-disturbance density in about 5 weeks. Finally, in terms of environmental conditions that fostered resilience, we acknowledge that both control and other un-manipulated bromeliads in the study area certainly provided a substantial pool of colonists. It is likely that the external source of colonists would be depleted and the rate of recovery less rapid if the whole forest (all bromeliads in the area) was subjected to an exceptionally severe drought. This situation compares to that of perennial wetlands that contribute species to seasonal wetlands in regions with a Mediterranean climate (Sim et al., 2013), and to immigration from source patches that prevents extinction in sink populations (Holyoak, 2000). The effects of real droughts on the potential resilience of invertebrate communities would thus depend upon the spatial extent of droughts (local or extensive) compared to the spatial scale of our experiment, but also on the patchiness of the disturbance (sensu Lopez-Hoffman et al., 2013). For instance, drought-induced tree mortality can be patchy within forests (Breshears et al., 2005), resulting in heterogeneous impacts on the understorey environments in terms of evaporation rates, humidity, throughfall upon rewetting, etc. Assuming that we would be able to experimentally dry up a larger portion of the forest or a larger number of bromeliad patches, we expect that the functional traits associated with invertebrate species' resistance to drought in bromeliads (this study) would remain unchanged. Typically, most species would resist a $90 \%$ decline in water volume available in their individual bromeliads, and culicid would certainly withstand a $99 \%$ decrease in water volume whatever the spatial extent of drought. However, because the rates (and predictability) of recolonisation strongly depend on the extent of source patches, we would expect resilience time and/or capacity to decrease with an increasing spatial extent and patchiness of disturbance.

In conclusion, although uncertainties remain as regards resilience patterns (see above), the results of our manipulative experiment predict that the trait structure of bromeliad invertebrate communities could remain stable under scenarios of precipitation change that would triple the duration of current dry periods, at least at a local scale. Once we account for variation in bromeliad hydrology during dry periods (i.e. for a fixed decrease in water level), however, it is likely that spatial variations in community structure (e.g. presence or absence of large-bodied predators) with local environmental conditions (i.e. open versus closed forest canopies) will mediate the tipping point between resistance to drought and a collapse in ecosystem processes. For instance, Brouard et al. (2012) compared the detrital food web of understorey bromeliads (forest sites, as in this study) and the detrital-algal-based food web of overstorey bromeliads (sun-exposed) in French Guiana. Not only did these authors suggest that the main trophic pathways are different in these two types of bromeliads, but they also highlighted a higher density of large-bodied predators (odonates, Toxorhynchites Diptera) and a lower density of filter feeders (Wyeomyia culicids) in sun-exposed bromeliads (see also Dézerald et al., 2013). Where bromeliad-dwelling odonates are common, they strongly influence community structure through top-down effects (Petermann et al., 2015), but they are more sensitive to desiccation than their common prey (e.g. culicid and chironomid larvae). Hence, one may assume that important functional shifts should occur earlier during the dry phase in an overstorey bromeliad than in an understorey bromeliad. Assuming that communities resist drought for a few weeks before drastic functional shifts occur in the system, further experimental study would therefore be needed to determine the extent to which species turnover and food-web structure determine this tipping point.

(C) 2015 John Wiley \& Sons Ltd, Freshwater Biology, 60, 1917-1929 


\section{Acknowledgments}

We are grateful to Frédéric Petitclerc, Clément Andrzejewski and the members of Hydreco (Laboratoire Environnement Petit Saut) for field and technical support, and to Stanislas Talaga for the identification of culicid species. We wish to thank Andrea Yockey-Dejean for proofreading the English text and Dr. Mark Kurtis Trzcinski, Dr. Alan Hildrew and two anonymous reviewers for providing insightful comments on an earlier version of the manuscript. Financial support was provided by the Agence Nationale de la Recherche through the Rainwebs project (Grant ANR-12-BSV70022-01) and an "Investissement d'Avenir" grant (Labex CEBA, ref. ANR-10-LABX-0025). OD's financial support was provided by a PhD fellowship from the CNRS and the FSE (Fond Social Européen). All authors certify that they have no conflict of interest.

\section{References}

Boersma K.S., Bogan M.T., Henrichs B.A. \& Lytle D.A. (2014) Invertebrate assemblages of pools in arid-land streams have high functional redundancy and are resistant to severe drying. Freshwater Biology, 59, 491-501.

Bogan M.T. \& Lytle D.A. (2011) Severe drought drives novel community trajectories in desert stream pools. Freshwater Biology, 56, 2070-2081.

Bond N., Lake P.S. \& Arthington A. (2008) The impacts of drought on freshwater ecosystems: an Australian perspective. Hydrobiologia, 600, 3-16.

Boersma K.S., Bogan M.T., Henrichs B.A. \& Lytle D.A. (2014) Invertebrate assemblages of pools in aridland streams have high functional redundancy and are resistant to severe drying. Freshwater Biology, 59, 491501.

Boulton A.J. (2003) Parallels and contrasts in the effects of drought on stream macroinvertebrate assemblages. Freshwater Biology, 48, 1173-1185.

Breshears D.D., Cobb N.S., Rich P.M., Price K.M., Allen C.D., Balice R.G. et al. (2005) Regional vegetation die-off in response to global-change-type drought. Proceedings of the National Academy of Sciences of the USA, 102, 1514415148.

Brouard O., Céréghino R., Corbara B., Leroy C., Pélozuelo L., Dejean A. et al. (2012) Understorey environments influence functional diversity in tank-bromeliad ecosystems. Freshwater Biology, 57, 815-823.

Céréghino R., Leroy C., Carrias J.F., Pélozuelo L., Ségura C., Bosc C. et al. (2011) Ant-plant mutualisms promote functional diversity in phytotelm communities. Functional Ecology, 25, 954-963.
Céréghino R., Oertli B., Bazzanti M., Coccia C., Compin A., Biggs J. et al. (2012) Biological traits of European pond macroinvertebrates. Hydrobiologia, 689, 51-61.

Chase J.M. (2007) Drought mediates the importance of stochastic community assembly. Proceedings of the National Academy of Sciences of the USA, 104, 17430-17434.

Chevenet F., Dolédec S. \& Chessel D. (1994) A fuzzy coding approach for the analysis of long-term ecological data. Freshwater Biology, 31, 295-309.

Clark T.M., Flis B.J. \& Remold S.K. (2004) pH tolerances and regulatory abilities of freshwater and euryhaline Aedine mosquito larvae. Journal of Experimental Biology, 207, 2297-2304.

Dedieu N., Rhone M., Vigouroux R. \& Céréghino R. (2015) Assessing the impact of gold mining in headwater streams of Eastern Amazonia using Ephemeroptera assemblages and biological traits. Ecological Indicators, 52, 332-340.

Dejean A., Céréghino R., Carpenter J.M., Corbara B., Hérault B., Rossi V. et al. (2011) Climate change impact on Neotropical social wasps. PLOS ONE, 6, e27004.

Dézerald O., Leroy C., Corbara B., Carrias J.-F., Pélozuelo L., Dejean A. et al. (2013) Food-web structure in relation to environmental gradients and predator-prey ratios in tank-bromeliad ecosystems. PLoS ONE, 8, e71735.

Dolédec S., Phillips N., Scarsbrook M., Riley R.H. \& Townsend C.R. (2006) Comparison of structural and functional approaches to determining landuse effects on grassland stream invertebrate communities. Journal of the North American Benthological Society, 25, 44-60.

Fenoglio S., Bo T., Cucco M. \& Malacarne G. (2007) Response of benthic invertebrate assemblages to varying drought conditions in the Po river (NW Italy). Italian Journal of Zoology, 74, 191-201.

Gascon S., Boix D., Sala J. \& Quintana X.D. (2010) Relation between macroinvertebrate life strategies and habitat traits in Mediterranean salt marsh ponds (Empordà wetlands, NE Iberian Peninsula). Hydrobiologia, 597, 7183.

Givnish T.J., Barfuss M.H.J., Van Ee B., Riina R., Schulte K., Horres R. et al. (2011) Phylogeny, adaptive radiation, and historical biogeography in Bromeliaceae: insights from an eight-locus plastid phylogeny. American Journal of Botany, 98, 872-895.

Hammill E., Atwood T.B., Corvalan P. \& Srivastava D.S. (2015) Behavioural responses to predation may explain shifts in community structure. Freshwater Biology, 60, 125135, doi:10.1111/fwb.12475.

Holyoak M. (2000) Habitat subdivision causes changes in food web structure. Ecology Letters, 3, 509-515.

IPCC (2013) Climate change 2013: the physical science basis. Working Group I Contribution to the IPCC. Fifth Assessment Report. Cambridge: Cambridge University Press. 1535 p. Accessed online 24 January 2015 at: http:// www.ipcc.ch/report/ar5/wg1/. 
Jabiol J., Corbara B., Dejean A. \& Céréghino R. (2009) Structure of aquatic insect communities in tank-bromeliads in a East-Amazonian rainforest in French Guiana. Forest Ecology and Management, 257, 351-360.

Jocque M., Kernahan A., Nobes A., Willians C. \& Field R. (2010) How effective are non-destructive sampling methods to assess aquatic invertebrate diversity in bromeliads? Hydrobiologia, 649, 293-300.

Juliano S.A. \& Lounibos L.P. (2005) Ecology of invasive mosquitoes: effects on resident species and on human health. Ecology Letters, 8, 558-574.

Karmalkar A.V., Bradley R.S. \& Diaz H.F. (2008) Climate change scenarios for Costa Rican montane forests. Geophysical Research Letters, 35, L11702.

Lake P.S. (2003) Ecological effects of perturbation by drought in flowing waters. Freshwater Biology, 48, 1161-1172.

Lake P.S. (2011) Drought and Aquatic Ecosystems: Effects and Responses. Wiley-Blackwell, Oxford, U.K.

Lamanna C., Blonder B., Violle C., Kraft N.J.B., Sandel B., Simova I. et al. (2014) Functional trait space and the latitudinal diversity gradient. Proceedings of the National Academy of Sciences of the USA, 111, 13745-13750.

Ledger M.E., Edwards F.K., Brown L.E., Milner A.M. \& Woodward G. (2011) Impact of simulated drought on ecosystem biomass production: an experimental test in stream mesocosms. Global Change Biology, 17, 22882297.

Leroy C., Carrias J.-F., Corbara B., Pélozuelo L., Dézerald O., Brouard O. et al. (2013) Mutualistic ants contribute to tank-bromeliad nutrition. Annals of Botany, 112, 919926.

Lopez L.C.S., Filizola B., Deiss I. \& Rios R.I. (2005) Phoretic behaviour of bromeliad annelids (Dero) and ostracods (Elpidium) using frogs and lizards as dispersal vectors. Hydrobiologia, 549, 15-22.

Lopez-Hoffman L., Breshears D.D., Allen C.D. \& Miller M.L. (2013) Key landscape ecology metrics for assessing climate change adaptation options: rate of change and patchiness of impacts. Ecosphere, 4, 101.

Magrin G.O., Marengo J.A., Boulanger J.-P., Buckeridge M.S., Castellanos E., Poveda G. et al. (2014) Central and South America. In: Climate Change 2014: Impacts, Adaptation, and Vulnerability. Part B: Regional Aspects. Contribution of Working Group II to the Fifth Assessment Report of the Intergovernmental Panel on Climate Change. (Eds V.R. Barros, C.B. Field, D.J. Dokken, M.D. Mastrandrea, K.J. Mach, T.E. Bilir, M. Chatterjee, K.L. Ebi, Y.O. Estrada, R.C. Genova, B. Girma, E.S. Kissel, A.N. Levy, S. MacCracken, P.R. Mastrandrea \& L.L. White), pp. 1499-1566. Cambridge University Press, Cambridge, U.K. and New York, NY, U.S.A.

McGill B.J., Enquist B.J., Weiher E. \& Westoby M. (2006) Rebuilding community ecology from functional traits. Trends in Ecology \& Evolution, 21, 178-185.
Merritt R.W., Cummins K.W. \& Berg M.B. (2008) An Introduction to Aquatic Insects of North America, 4th edn. Kendall/Hunt Publishing Company, Dubuque, IA, pp. 1158.

Naiman R.J. \& Dudgeon D. (2011) Global alteration of freshwaters: influences on human and environmental well-being. Ecological Research, 26, 865-873.

Petermann J.S., Farjalla V.F., Jocque M., Kratina P., MacDonald A.A.M., Marino N.A.C. et al. (2015) Dominant predators mediate the impact of habitat size on trophic structure in bromeliad invertebrate communities. Ecology, 96, 428-439.

Pillar V.D., Duarte L.D., Sosinski E.E. \& Joner F. (2009) Discriminating trait-convergence and trait-divergence assembly patterns in ecological community gradients. Journal of Vegetation Science, 20, 334-348.

Poff N.L., Olden J.D., Vieira N.K.M., Finn D.S., Simmons M.P. \& Kondratieff B.C. (2006) Functional trait niches of North American lotic insects: traits-based ecological applications in light of phylogenetic relationships. Journal of the North American Benthological Society, 25, 730-755.

Power M.E., Parker M.S. \& Dietrich W.E. (2008) Seasonal reassembly of a river food web: floods, droughts, and impacts of fish. Ecological Monographs, 78, 263-282.

R Development Core Team (2014) R: A Language and Environment for Statistical Computing. R Foundation for Statistical Computing, Vienna, Austria. Accessed online 31 October 2014 at: http:/ /www.R-project.org/.

Reznickova P., Paril P. \& Zahradkova S. (2007) The ecological effect of drought on the macroinvertebrate fauna of a small intermittent stream - An example from the Czech Republic. International Review of Hydrobiology, 92, 514-526.

Richardson B.A. (1999) The bromeliad microcosm and the assessment of faunal diversity in a Neotropical forest. Biotropica, 31, 321-336.

Sangiorgio F., Fonnesu A. \& Mancinelli G. (2007) Effect of drought frequency and other reach characteristics on invertebrate communities and litter breakdown in the intermittent Mediterranean river Pula (Sardinia, Italy). International Review of Hydrobiology, 92, 156-172.

Sheldon K.S., Yang S. \& Tewksbury J.J. (2011) Climate change and community disassembly: impacts of warming on tropical and temperate montane community structure. Ecology Letters, 14, 1191-1200.

Sim L.L., Davis J.A., Strehlow K., Mcguire M., Trayler K.M., Wild S. et al. (2013) The influence of changing hydroregime on the invertebrate communities of temporary seasonal wetlands. Freshwater Science, 32, 327-342.

Southwood T.R.E. (1988) Tactics, strategies, and templets. Oikos, 52, 3-18.

Srivastava D.S. (2006) Habitat structure, trophic structure and ecosystem function: interactive effects in a bromeliad-insect community. Oecologia, 149, 493-504.

Srivastava D.S., Kolasa J., Bengtsson J., Gonzalez A., Lawler S.P., Miller T.E. et al. (2004) Are natural microcosms use- 
ful model systems for ecology? Trends in Ecology and Evolution, 19, 379-384.

Statzner B., Bis B., Doledec S. \& Usseglio-Polatera P. (2001) Perspectives for biomonitoring at large spatial scales: a unified measure for the functional composition on invertebrate communities in European running waters. Basic and Applied Ecology, 2, 73-85.

Violle C., Reich P.B., Pacala S.W., Enquist B.J. \& Kattge J. (2014) The emergence and promise of functional biogeography. Proceedings of the National Academy of Sciences of the USA, 111, 13690-13696.
Williams D. \& Hynes H.B.N. (1974) The occurrence of benthos deep in the substratum of a stream. Freshwater Biology, 4, 233-256.

Zotz G. \& Thomas V. (1999) How much water is in the tank? Model calculations for two epiphytic bromeliads. Annals of Botany, 83, 183-192.

(Manuscript accepted 26 May 2015) 